\title{
BILATERAL LOWER MOTOR NEURON FACIAL NERVE PALSY DUE TO HIV SEROCONVERSION
}

\author{
R Dolan, $M B C h B, M A, B A$ \\ University of Dundee Medical School, UK \\ D Maritz, $M B C h B$ \\ L Wallis, $M B C h B, F C E M, M D$ \\ Division of Emergency Medicine, University of Cape Town and Stellenbosch University, W Cape \\ M Parak, $M B B S$ \\ G F Jooste Hospital, Cape Town
}

A 34-year-old-woman presented with acute onset of headache and bilateral facial nerve paralysis. On examination bilateral lower motor neuron 7 th cranial nerve palsy in keeping with bilateral Bell's palsy was apparent. Investigations showed aseptic meningitis, with a low CD4 count of 352 cells $/ \mu$ land an elevated viral load (5 300 counts $/ \mathrm{ml}, \log =$ 3.72 ), in keeping with acute HIV infection. Bell's palsy is a known complication of seroconversion - 13 cases have been reported worldwide. To our knowledge this is the first reported case in South Africa.

\section{CASE REPORT}

A 34-year-old woman presented with a 1-week history of occipital headache and acute-onset bilateral facial weakness that resulted in her being unable to close her mouth and eyes. No visual deficits were noted, but her sense of taste was markedly reduced. She had no past medical history of note and was on no medications.

On examination she was apyrexial, with a blood pressure of $140 / 123 \mathrm{mmHg}$ and a pulse rate of 113 beats/min. There was complete bilateral lower motor neuron 7 th cranial nerve palsy in keeping with bilateral Bell's palsy. She was unable to close her eyes or mouth on request and could not speak without the support of her hand. No other focal neurology was present. There was a small aphthous ulcer on her upper palate.

A lumbar puncture, which was unfortunately traumatic, resulted in a cerebrospinal fluid reading with elevated erythrocytes $\left(10000 \times 10^{9} / \mathrm{l}\right)$ and protein $4.16 \mathrm{~g} / \mathrm{l}$. However, after corrections were made using blood sample cell levels the CSF showed evidence of aseptic meningitis with elevated polymorphs $\left(5 \times 10^{9} /\right)$ and lymphocytes $\left(299 \times 10^{9} / l\right)$ as well as a glucose level towards the lower end of normal at $2.3 \mathrm{mmol} / \mathrm{l}$. Consent to conduct HIV testing was obtained, and while the rapid test was negative, the CD4 count was reduced at 352 cells/ $\mu \mathrm{l}$ and the viral load was elevated at 5300 counts/ $\mathrm{ml}(\log =3.72)$, a result in keeping with an acute HIV infection and seroconversion illness.

The patient was informed of the likelihood of seroconversion, and booked for an enzyme-linked immunosorbent assay (ELISA) HIV test in 6 weeks. She was discharged on oral acyclovir in order to cover any underlying herpes simplex infection, nystatin to cover fungal infections, and an artificial tear solution to prevent drying out of the eyes. Simple analgesia was provided and a follow-up magnetic resonance imaging scan and ENT consultation were organised.

\section{DISCUSSION}

Bilateral facial nerve palsy is a rare but recognised complication of seroconversion, the process by which the HIV virus becomes widespread throughout the body. ${ }^{1}$ The presence of acute HIV infection in this case is supported by the low CD4 count and high viral load. In $40-90 \%$ of patients with a new HIV infection an acute seroconversion illness occurs between 2 and 6 weeks after exposure. Typical symptoms include fever, fatigue, pharyngitis, weight loss, night sweats, lymphadenopathy, myalgias, headache, nausea and diarrhoea. ${ }^{1}$ While this patient did not suffer from the majority of these symptoms, she did have a severe headache (resulting in vomiting) and aseptic meningitis, both of which have previously been described in seroconversion. ${ }^{1}$

The first case of bilateral 7 th cranial nerve palsy as part of an acute seroconversion reaction was reported in 1989 in a 45-year-old homosexual postgraduate student in California. ${ }^{2}$ Since then only 14 other cases have been reported in the literature worldwide, including our own (which to our knowledge is the first case in South Africa). ${ }^{3}$ In the 14 cases described, ages ranged from 21 to 73 years, and $71.4 \%$ were men. ${ }^{3}$ Sexual transmission was the means of acquiring HIV in $64.3 \%$ of cases, and the median interval between the onset of symptoms of HIV infection and the development of 7 th cranial nerve palsy was 15 days (range 2 - 180 days). Aseptic meningitis and a maculopaular rash were present in the majority of 
cases. All patients who had a recorded CD4 cell count had counts over 300 cells $/ \mu$ l (range 323 - 825 cells $/ \mu l$ ). Three patients had additional neurological symptoms at diagnosis, while just one patient received antiretroviral therapy. All but one patient made a complete recovery in terms of their nerve paralysis.

The pathogenic mechanism of bilateral Bell's palsy in patients with acute HIV infection is not completely understood. There are several schools of thought as to how this rare sign appears, including a proposed direct insult to the ne rve by the HIV virus. Another possibility would be immunologically mediated inflammatory polyradiculopathy, similar to a regional Guillain-Barré syndrome, which would make more sense immunologically and therefore has slightly more scientific merit; however, neither theory has yet been fully tested. ${ }^{3}$

Facial nerve paralysis has a high predictive value for HIV infection in populations with high rates of seroconversion, including those who engage in highrisk activities such as intravenous drug users and men who have sex with men, and patients from HIVendemic areas such as sub-Saharan Africa. ${ }^{4}$ This case and the supportive evidence from the literature would indicate the necessity of including acute seroconversion syndrome in a list of differential diagnoses for bilateral facial nerve palsy, especially in sexually active patients who have had a prior acute febrile illness with rash or headache. A full HIV work-up should form part of the investigation of bilateral Bell's palsy.

This case report was approved by the Health Research Ethics Committee, Stellenbosch University.

\section{REFERENCES}

1. Kassutto S, Rosenberg ES. Primary HIV type 1 infection. Clin Infect Dis 2004;38:1447-1453

2. Wechsler AF, Ho DD. Bilateral Bell's palsy at the time of HIV seroconversion. Neurology 1989; 39:747-748.

3. Serrano P, Hernandez N, Arroyo JA, et al. Bilateral Bell palsy and acute HIV type 1 infection: report of 2 cases and review. Clin Infect Dis 2007;44:57-61.

4. Youle M. AIDS and the British healthcare system. J Int Assoc Physicians AIDS Care 1997;3:34-38. 